\title{
A comparison of multiple imputation methods for bivariate hierarchical data: an application to cost-effectiveness analyse
}

\author{
K Diaz-Ordaz*, M Gomes, R Grieve, MG Kenward \\ From 2nd Clinical Trials Methodology Conference: Methodology Matters \\ Edinburgh, UK. 18-19 November 2013
}

\section{Background}

Missing data are common in cluster randomised trials (CRTs) and may lead to biased and inefficient estimation. Multiple imputation (MI) is often used but, to obtain valid inferences, the imputation model must recognise the data structure.

We compare complete case, random-effects MI, fixedeffects MI, and single-level MI, when the analysis model is a linear mixed-model.

\section{Methods}

We begin by illustrating the MI approaches with an example, a cost-effectiveness analysis of a CRT evaluating an intervention for postnatal depression (2659 participants, 100 clusters ICC for cost 0.17 , ICC for QALYs $0.04)$. We conducted a simulation study to assess the performance of the alternative methods. Missing data scenarios were simulated according to factors hypothesized to influence performance, amongst them ICCs, number and size of clusters and the proportion of missing data.

\section{Results}

In the case-study, incremental net benefit estimates (SE) were 81.39 (36.02) for the multilevel MI, 61.72 (36.62) for the fixed effects MI, and 96.00 (50.80) for the singlelevel MI. In the simulation, complete case resulted in biased estimates (percentage bias between 22\% and $60 \%$ ), while multilevel MI resulted on estimates which were only moderately biased (percentage bias range 0,003\%, 3.35\%). Fixed effects MI over-estimated the SEs, resulting in CI coverage in excess of nominal levels

LSHTM, London, UK (up to $100 \%$ ), whereas multilevel MI reported coverage levels of approximately $95 \%$ throughout.

\section{Conclusion}

Estimates may differ depending on how the MI accounted for clustering. Multilevel MI performed well across the settings considered and is appropriate for studies that have a hierarchical design.

Published: 29 November 2013

doi:10.1186/1745-6215-14-S1-098

Cite this article as: Diaz-Ordaz et al:: A comparison of multiple imputation methods for bivariate hierarchical data: an application to cost-effectiveness analyse. Trials 2013 14(Suppl 1):O98.

Submit your next manuscript to BioMed Central and take full advantage of:

- Convenient online submission

- Thorough peer review

- No space constraints or color figure charges

- Immediate publication on acceptance

- Inclusion in PubMed, CAS, Scopus and Google Scholar

- Research which is freely available for redistribution 